\title{
Effectiveness of Aromatherapy with Lavender Oil in Relieving Post Caesarean Incision Pain
}

\author{
Mohamed Abdel-Hamed Metawie ${ }^{1}$, Hadayat AbdEl-Raof Amasha ${ }^{2}$, Ragaa Ali Abdraboo ${ }^{3}$, \\ Sally Ebrahim $\mathrm{Ali}^{4}$ \\ ${ }^{1}$ Dean of Faculty of Medicine, Port-Said University, Port-Said, Egypt \\ ${ }^{2}$ Gynecological \& Obstetrical Nursing, Faculty of Nursing, Port Said University, Port-Said, Egypt \\ ${ }^{3}$ Faculty of Nursing, Cairo University, Cairo, Egypt \\ ${ }^{4}$ Governmental Hospital, El-Manzala, Egypt
}

Email address:

mohmetawie@hotmail.com (M. Abdel-Hamed Metawie)

\section{To cite this article:}

Mohamed Abdel-Hamed Metawie, Hadayat AbdEl-Raof Amasha, Ragaa Ali Abdraboo, Sally Ebrahim Ali. Effectiveness of Aromatherapy with Lavender Oil in Relieving Post Caesarean Incision Pain. Journal of Surgery. Special Issue: Postoperative Pain Syndrome.

Vol. 3, No. 2-1, 2015, pp. 8-13. doi: 10.11648/j.js.s.2015030201.12

\begin{abstract}
Background: Post caesarean section pain is a common cause of pain in obstetrics, safe pain control methods after caesarean section is a greater challenge for health care providers because the spread use of drugs can cause side effects. Nonpharmacological measures are safer with fewer side effects than pharmacological measures. Aim: The aim of the current study was to evaluate the effectiveness of aromatherapy with lavender oil in relieving post caesarean incision pain. Design: A quasiexperimental design comprising two groups was used, with a sample of convenience of 100 post caesarean section mothers. The study was conducted at the postpartum unit in Suez Canal University Hospital, Ismailia City, Egypt between October 2013 and January 2014. Fifty mothers comprising the experimental group were inhaled $1 \mathrm{cc}$ of lavender essential oil via an oxygen facemask and used for three minutes, while fifty participants of the control group were given placebo then the pain level was assessed after half an hour using Visual Analogue Scale (VAS) and Modified Johanson Pain-O-Meter (MJPOM). Results of the study showed that, aromatherapy with lavender oil via oxygen facemask effectively relieving post caesarian incision pain, and highly statistically significant differences in pain intensity between the groups understudy $(\mathrm{p}<0.001)$ was observed. Conclusion: Lavender oil is a successful relieving pain after caesarean section. Therefore, hospital staff managers are encouraged to establish standards of aromatherapy care in maternity department and add aromatherapy concepts and techniques in the continued training program of nurses and midwives.
\end{abstract}

Keywords: Aromatherapy, Caesarean Section, Lavender Oil, Pain

\section{Introduction}

Caesarean section (CS) is the most common operation all over the world, the rate of this operation reaches near $50 \%$ of all types of deliveries ${ }^{(1)}$. Pain is a major problem in surgery, including post cesarean section pain and pain relief and patient satisfaction are still inadequate in many cases ${ }^{(2)}$. Pain can make the recovery difficult and delays mothers to get in touch with the newborns, besides being an obstacle to a good breastfeeding position, self-care, newborn care, and to do daily activities ${ }^{(3)}$. Therefore, relieving post caesarean pain is an issue that cannot be ignored. Non-pharmacological methods increased the individual control feeling, decreased the feeling of weakness, improved the activity level and functional capacity, and reduced the needed dosage of analgesic drugs thus decreasing the side effects of the treatment ${ }^{(4)}$. In recent years, many complementary therapies such as herbal medicines and aromatherapy are tried to help manage pain ${ }^{(5)}$.

Aromatherapy is one of the non-pharmacological methods for pain relief and lavender has analgesic properties. However, lavender oil is commonly used in aromatherapy that the scent of the essential oil from the flowers is inhaled (6). Lavender oil used to alleviate pain in different conditions such as changing dressings, palliative care, to control labor pain as well as chronic pain ${ }^{(7)}$. Some researchers concluded 
that aromatherapy by using lavender essence is effective in reducing pain after caesarean section ${ }^{(8)}$, as inhaled lavender essence $^{(9)}$ and massage with lavender oil ${ }^{(10,11)}$.

\section{Methods}

\subsection{Design}

A quasi-experimental design was used in the current study. This study was conducted at Postpartum Unit affiliated to Suez-Canal University Hospital, Egypt. The hospital introduces teaching facilities and provides maternal and child services around the clock, free charge.

\subsection{Subjects}

A sample of convenience of 100 mothers post CS, were selected and assigned into two groups: group I was the study group consisted of 50 mothers; and group II was the control group consisted of 50 mothers. Both study and control groups were selected according to the following inclusion criteria: age from 21 - 35 years old, full term, after six hours of operation, spinal anesthesia and not suffering from medical and/or gynecological health problems.

\subsection{Data Collection Instruments}

Based on related literature review; the researchers used three data collection tools related to socio-demographic, history of current pregnancy, and pain assessment. Questions regarding the socio-demographic data included mothers' age, educational level, occupation, and their residence. History of current pregnancy include weeks of gestation, parity and gravidity. Other variables included antenatal care and question regarding the wanted and unwanted pregnancy.

Visual Analog pain Scale (VAS) was used to assess the degree of pain, and a Modified Version of Johansson Pain-OMeter (MJPOM) (1996) to measure the intensity of sensory and affective components of pain ${ }^{(12)}$.

\subsection{Procedure of the Study}

The study proceeded as follows: before carrying out the lavender oil implementation, the $4^{\text {th }}$ author (Ali S.E) made sure that each mother met the inclusion criteria, and willingly agreed to the participate. The researcher explained briefly the aim of the study and the procedure to the participants and taught them how to report their degree of pain using the VAS.

The mothers took the routine treatment of the hospital as post CS pain relief measures, and after six hours (when the anesthesia had fully worn off), a researcher gave the experimental group $1 \mathrm{cc}$ of lavender oil (applied with a cotton swab to the inside of an $\mathrm{O}_{2}$ face mask and used for three minutes). In addition, the researcher gave oxygen through a face mask with the placebo for three minutes to mothers in control group. The researcher evaluated the pain after half an hour, using VAS and MJPOM, for the two groups. Finally, the researchers coded and transformed the row data into coding sheets and then, analysis and interpretation of the collected data were done. Three days per week were specified for data collection (Sunday, Tuesday \& Thursday) over a period of data of four months from the beginning of October 2013 tell ending of January 2014).

\subsection{Ethical Considerations}

Approval was obtained from the Dean of Faculty of Nursing at Port Said University and directors of Suez Canal University Hospital. The purpose of the study was explained to each mother and an informed consent was obtained from each of those who agreed to participate. They were assured about confidentiality and privacy and that this information will be used only for research purposes.

\subsection{Statistical Analysis of Data}

Data entry was done using Epi-Info 6.04 computer software package, while statistical analysis was done using the statistical package for social sciences (SPSS), version 15.0. Data were presented using descriptive statistics in the form of frequencies and percentages for qualitative variables, means and standard deviations for quantitative variables.

Qualitative variables were compared using Chi square test $\left(\chi^{2}\right)$ as the test of significance, the $p$-value is the degree of significance, and the correlation (r) test was used. A significant level value was considered when $p$-value $\leq 0.05$, while a highly significant level value was considered when $\mathrm{p}$ value $\leq 0.001$, and $p$-value $>0.05$ indicates non-significant results.

\subsection{Operational Definition}

Aromatherapy: The essential lavender oil of the experimental group is pure plant oil, bought from Zamzam factory established under the supervision of the Ministry of Health, Egypt (No. 108/ 2008).

Incision pain: Refers to the mother's subjective pain selfreport and pain observation by Visual Analogue Scale (VAS), it was developed by Melzack and Katz (1999) ${ }^{(12)}$. It comprises 10 points numerical scale, corresponding to the degree of pain, where zero indicates no pain, 10 indicates the worst pain.

Modified Version of Johansson Pain-O-Meter (MJPOM), was developed by Johansson, (1996) ${ }^{(13)}$. It was used to measure the intensity of sensory and affective components of pain, where the mother's choice of words is calculated to determine pain intensity. One up to three indicates mild pain, four up to six indicate moderate pain, and seven up to nine indicate severe pain and finally, 10 indicates the worst pain.

\section{Results}

The mean age of the study group was $27.22 \pm 4.4$, years and that of the control group was $26.2 \pm 3.8$ years. Figure 2 illustrates that $32.0 \%$ of the study group and $30 \%$ of the control group were illiterate. Meanwhile, only 6.0 of the study group and few percent $(2.0 \%)$ of the control group graduated from university. 


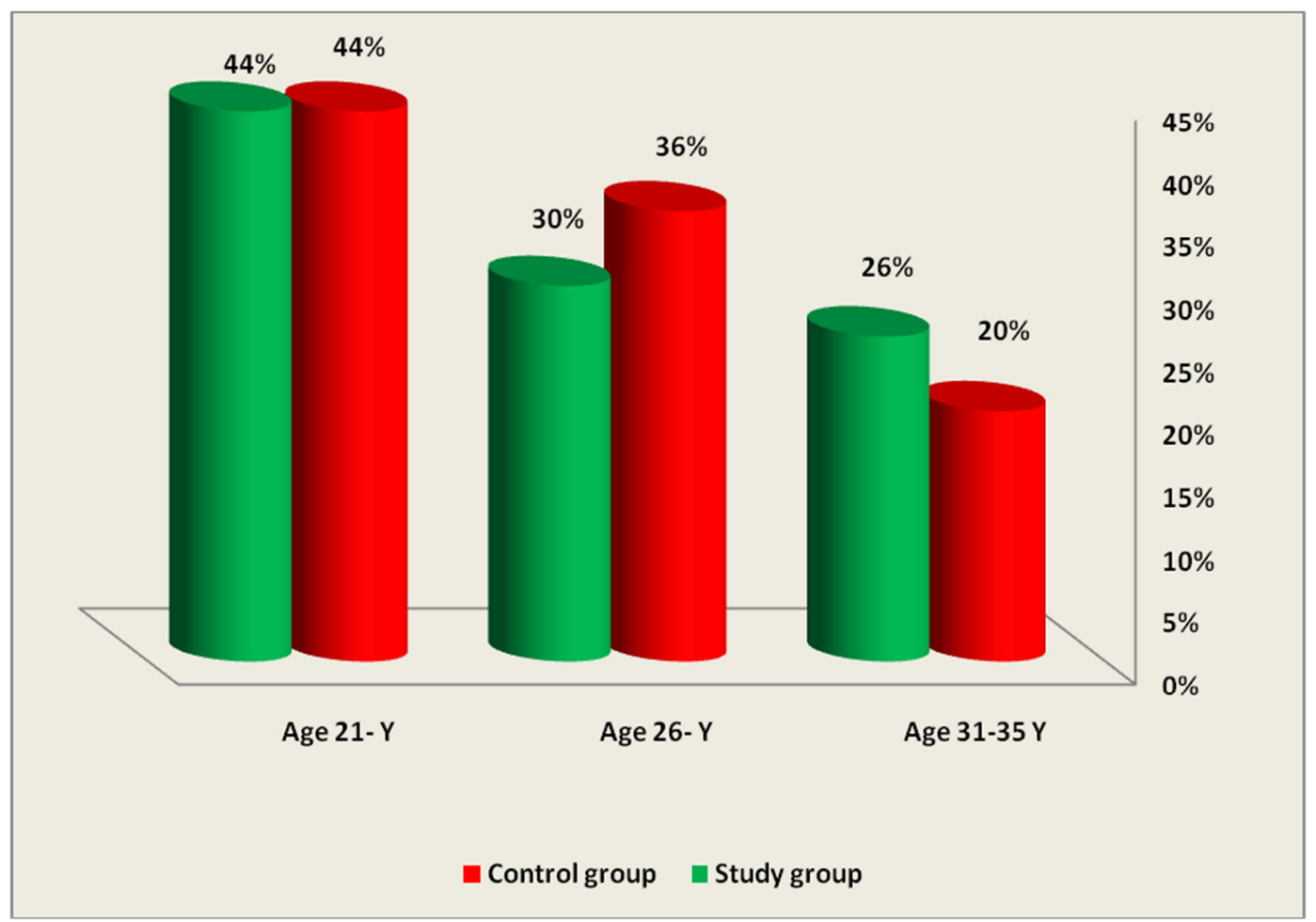

Fig. (1). Distribution of the study and control groups according to their age $(n=100)$.

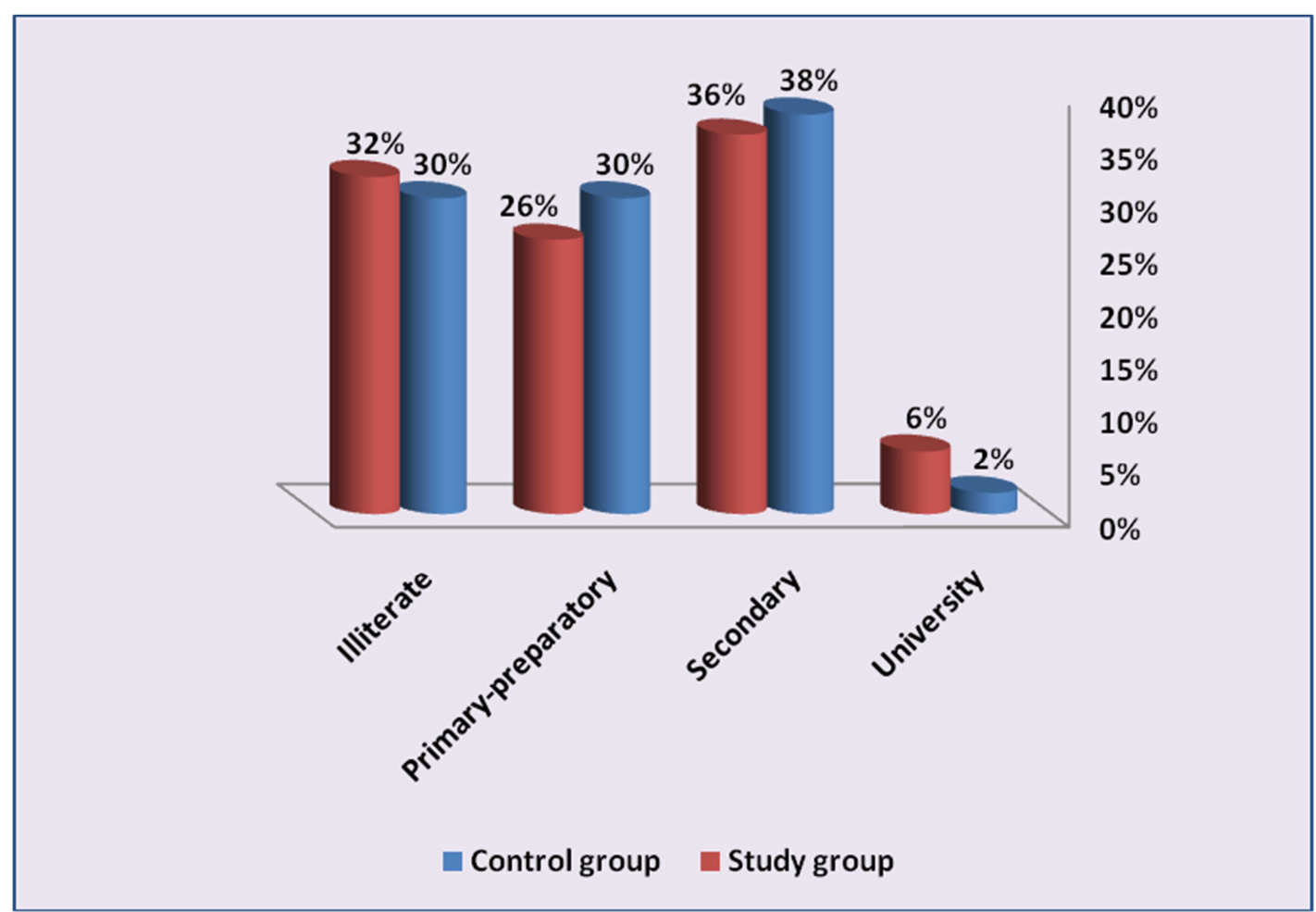

Fig. (2). Distribution of the study and control groups according to their educational level ( $n=100)$.

As regards post-cesarean incision pain intensity measured by visual analogue scale (VAS), the results reveal that, $16.0 \%$ of the study group had experienced mild pain compared to none of the control group. Seventy percent of the study group had experienced moderate pain compared to $18.0 \%$ of the control group; $2.0 \%$ of the study group had experienced the worst pain, while $28.0 \%$ of the control group had experienced the worst pain. A highly statistically significant difference was found between both groups $(\mathrm{p}<0.001)$ (table 1$)$. 
Table 1. Distribution of the study and control groups according to their incision pain level as recorded by the Visual Analogue Scale (VAS) \& Modified Version of Johansson Pain-O-Meter MJPOM $(n=100)$.

\begin{tabular}{|c|c|c|c|c|}
\hline \multirow{2}{*}{ Items } & Study Group $(\mathrm{n}=50)$ & Control Group (n=50) & \multirow{2}{*}{$\chi^{2}$} & \multirow{2}{*}{ Pvalue } \\
\hline & No (\%) & No (\%) & & \\
\hline \multicolumn{5}{|c|}{ Incision Pain Level by VAS } \\
\hline Mild & $8(16.0)$ & $0(0.0)$ & \multirow{6}{*}{52.10} & \multirow{6}{*}{$<0.001 * *$} \\
\hline Moderate & $35(70.0)$ & $9(18.0)$ & & \\
\hline Severe & $6(12.0)$ & $11(22.0)$ & & \\
\hline Very severe & $0(0.0)$ & $16(32.0)$ & & \\
\hline Worst & $1(2.0)$ & $14(28.0)$ & & \\
\hline \multicolumn{3}{|c|}{ Incision Pain Level by MJPOM } & & \\
\hline Mild & $0(0.0)$ & $0(0.0)$ & & \multirow{5}{*}{$<0.001 * *$} \\
\hline Moderate & $18(36.0)$ & $1(2.0)$ & \multirow{4}{*}{50.97} & \\
\hline Severe & $17(34.0)$ & $0(0.0)$ & & \\
\hline Very severe & $11(22.0)$ & $29(58.0)$ & & \\
\hline Worst & $4(08.0)$ & $20(40.0)$ & & \\
\hline
\end{tabular}

** Significant at $\mathrm{p}$-value $<0.001$

The same table shows distribution of pain intensity among both study and control groups as recorded by the Modified version of Johansson Pain-O-Meter (MJPOM). No one of both groups had reported mild pain, $36.0 \%$ of the study group had reported moderate pain compared to $2.0 \%$ of the control group, $34.0 \%$ of the study group had reported severe pain. While none of the control group reported severe pain, $22.0 \%$ of the study group reported very severe pain, versus $58.0 \%$ of the control group and $8.0 \%$ of the study group reported the worst pain compared to $40.0 \%$ of the control group reported the worst pain. A highly statistically significant difference was found between both groups $(\mathrm{p}<0.001)$.

It was noticed from table 2 that an $8 \%$ of the study group compared with $24.0 \%$ of the control group described their pain by the word "cutting", while $6.0 \%$ of the control group versus $2.0 \%$ of the study group described, their pain by the word "burning", a lesser percentage $2.0 \%$ of the control group described their pain by the word "cramping versus none of the study group. On the other hand, more than third of the control group (38.0\%) compared to $60.0 \%$ of the study group described their pain by the word "gnawing". Only $4.0 \%$ of the study group described their pain by the word "pinching", versus more of the control group, and $22.0 \%$ of the study group versus none of the control group described their pain by the word "stinging". A highly statistically significant difference was found between both groups in relation to pain intensity $(\mathrm{p}<0.001)$.

Table 2. Distribution of the study and control groups according to their incision pain intensity as recorded by the Modified Version of Johansson Pain-O-Meter (MJPOM) $(n=100)$

\begin{tabular}{|c|c|c|c|c|c|c|}
\hline \multirow{2}{*}{ Items } & \multicolumn{2}{|c|}{ Study group $(n=50)$} & \multicolumn{2}{|c|}{ Control group $(n=50)$} & \multirow{2}{*}{$\chi^{2}$} & \multirow{2}{*}{ P-value } \\
\hline & No & $\%$ & No & $\%$ & & \\
\hline \multicolumn{7}{|l|}{ Sensory Pain } \\
\hline Cutting & 4 & 8.0 & 12 & 24.0 & \multirow{10}{*}{35.80} & \multirow{10}{*}{$<0.001 * *$} \\
\hline Tearing & 0 & 0.0 & 0 & 0.0 & & \\
\hline Sharp & 0 & 0.0 & 3 & 6.0 & & \\
\hline Burning & 1 & 2.0 & 3 & 6.0 & & \\
\hline Cramping & 0 & 0.0 & 1 & 2.0 & & \\
\hline Aching & 2 & 4.0 & 1 & 2.0 & & \\
\hline Gnawing & 30 & 60.0 & 19 & 38.0 & & \\
\hline Pinching & 2 & 4.0 & 0 & 0.0 & & \\
\hline Stinging & 11 & 22.0 & 0 & 0.0 & & \\
\hline Sore & 0 & 0.0 & 0 & 0.0 & & \\
\hline \multicolumn{7}{|l|}{ Affective Pain } \\
\hline Torturing & 4 & 8.0 & 12 & 24.0 & \multirow{9}{*}{35.80} & \multirow{9}{*}{$<0.001 * *$} \\
\hline Suffocating & 0 & 0.0 & 3 & 6.0 & & \\
\hline Terrifying & 1 & 2.0 & 3 & 6.0 & & \\
\hline Dreadful & 0 & 0.0 & 1 & 2.0 & & \\
\hline Fearful & 0 & 0.0 & 11 & 22.0 & & \\
\hline Troublesome & 2 & 4.0 & 1 & 2.0 & & \\
\hline Tiring & 30 & 60.0 & 19 & 38.0 & & \\
\hline Irritating & 2 & 4.0 & 0 & 0.0 & & \\
\hline Nagging & 11 & 22.0 & 0 & 0.0 & & \\
\hline
\end{tabular}

** Significant at $\mathrm{p}$-value $<0.001$ 
The same table indicates that the word "tiring" was the most frequently used as an affective pain descriptor between the two groups (study, 60.0\% \& control, 38.0\%). However, the word "killing" was not used as an affective pain descriptor between the two groups. A highly statistically significant difference also was found between both groups in relation to pain intensity recorded $(\mathrm{p}<0.001)$.

Table 3 shows that there was a statistically significant relation between the effect of lavender oil and educational level $(\mathrm{p}<0.05)$. Lavender oil was more effective between educated mothers rather than non-educated ones. The same table shows relation between pain intensity according to the visual analogue scale and parity. A highly statistically significant difference was found between the effect of lavender oil and parity ( $\mathrm{p}<0.001$ ), lavender oil was more effective with multiparous than primiparous. However, there was no statistically significant relation between the others selected variables (antenatal care \& wanted pregnancy) and lavender oil inhalation post CS ( $\mathrm{p}=>0.05 \& 0.05$ respectively).

Table 3. Relation between pain intensity according to the visual analogue scale and selected variables to the study group ( $n=50)$.

\begin{tabular}{|c|c|c|c|c|c|c|c|}
\hline \multirow{3}{*}{ Selected Variables } & \multicolumn{5}{|c|}{ Pain Level } & & \multirow{3}{*}{ p-value } \\
\hline & Mild & Moderate & Severe & Very Severe & Worst & & \\
\hline & N (\%) & $\mathbf{N}(\%)$ & $\mathbf{N}(\%)$ & N (\%) & N (\%) & & \\
\hline \multicolumn{8}{|l|}{ Education } \\
\hline Non-educated $(\mathrm{n}=16)$ & $1(6.3)$ & $12(75.0)$ & $3(18.8)$ & $0(0.0)$ & $1(6.3)$ & \multirow{3}{*}{16.29 . } & \multirow{2}{*}{$<0.05^{*}$} \\
\hline Educated $(n=34)$ & $7(20.6)$ & $23(67.6)$ & $3(8.8)$ & $0(0.0)$ & $0(0.0)$ & & \\
\hline \multicolumn{7}{|l|}{ Parity } & \\
\hline $\operatorname{Para} 1(n=8)$ & $0(0.0)$ & $2.0(25.0)$ & $5(62.3)$ & $0(0.0)$ & $1(12.5)$ & \multirow{2}{*}{38.34} & \multirow{2}{*}{$<0.001 * *$} \\
\hline Para 3 or more $(n=31)$ & $8(25.8)$ & $23(74.8)$ & $0(0.0)$ & $0(0.0)$ & $0(0.0)$ & & \\
\hline \multicolumn{8}{|l|}{ Antenatal care } \\
\hline Yes $(n=42)$ & $5(11.9)$ & $32(76.2)$ & $4(9.5)$ & $0(0.0)$ & $1(2.4)$ & \multirow{2}{*}{1.70} & \multirow{2}{*}{$>0.05$} \\
\hline No $(n=8)$ & $3(37.5)$ & $3(37.5)$ & $2(25.0)$ & $0(0.0)$ & $0(0.0)$ & & \\
\hline \multicolumn{8}{|l|}{ Wanted pregnancy } \\
\hline Yes $(n=34)$ & $5(14.7)$ & $26(76.5)$ & $2(5.9)$ & $0(0.0)$ & $1(2.9)$ & \multirow{2}{*}{5.67} & \multirow{2}{*}{$>0.05$} \\
\hline No $(n=16)$ & $3(18.8)$ & $9(56.3)$ & $4(25.0)$ & $0(0.0)$ & $0(0.0)$ & & \\
\hline
\end{tabular}

* Significance at $<0.05$

Table 4. Correlation between Visual Analogue Scale score and Modified version of Johansson Pain-O-Meter (MJPOM)

\begin{tabular}{llc}
\hline \multirow{2}{*}{ Variables } & \multicolumn{3}{l}{ Modified version of Johansson Pain-O-Meter (JPOM) } \\
\cline { 2 - 3 } & $\mathbf{r}$ & p- value \\
\hline Visual Analogue Scale & $.522(* *)$ & .000 \\
\hline
\end{tabular}

** Correlation is significant at the 0.01 level (2-tailed).

Table 4 shows that there was a positive correlation between Visual Analogue Scale and Modified version of Johansson Pain-O-Meter $(r=.522$ at $\mathrm{p}=.000)$.

\section{Discussion}

The pain control after cesarean delivery is a great challenge for the health care provider because the spread use of drugs can cause side effects such as; nausea, vomiting and excessive sedation; and it can cause a delay in getting out of bed and discharge from the hospital. In addition, the drugs excrete in breast milk and can cause sedation in baby as well ${ }^{(14)}$. Pollard (2008) ${ }^{(15)}$, observed that the use of aromatherapy reduced the need for more invasive forms of pain management and has a positive effect on client satisfaction. Side effects of the oils were documented in only two cases (1\%); these side effects were skin irritation and headache. No adverse reactions were documented with regard to babies born in the birthing pool.

The result of current study goes in line with other studies stated that there was a significant reduction in pain level of postoperative cesarean section after inhaling lavender essence $^{(16,17)}$, on episiotomy pain using lavender oil bath at four hours and five days after delivery ${ }^{(18,19)}$.

The current study was in accordance with other studies reporting analgesic effect of lavender oil and decreased the number of required analgesics following tonsillectomy in pediatric patients ${ }^{(20)}$ and found that aromatherapy with lavender oil a good alternative to reduce normal labour pain and is more effective than breathing techniques ${ }^{(21)}$. Our data was also consistent with others of same interest who reported that aromatherapy with inhalation lavender essential oil is effective on anxiety and pain in IUD insertion ${ }^{(22)}$ and in reducing pain following needle insertion into a fistula in hemodialysis patients ${ }^{(9)}$.

\section{Conclusion}

In the light of the findings of the current study, it can be concluded that, lavender oil was an effective method in postoperative pain control with comparison to placebo treatment. Lavender oil inhalation appears to be an effective non-invasive and non-pharmacological intervention for postoperative pain management. The efficiency of intervention is 
found to be effective in pain reduction after 30 minutes, in relation to lavender oil inhalation it can be used as an effective nursing initiative in post cesarean section pain control.

\section{Recommendations}

Based on the findings and conclusion, the following recommendations can be suggested.

- Hospital managers are encouraged to include aromatherapy techniques in the training program for maternity nurses and recommended to be included in the hospital protocol for management of post-cesarean incision pain.

- Lavender oil inhalation for relieving post cesarean pain may be added in maternal nursing curricula of nursing schools.

\section{References}

[1] Ganji, F., Yusefi, H., \& Baradaran, A. Effect of a participatory intervention to reduce the number of unnecessary cesarean sections performed in Shahrekord of Iran. J. Medical Sci; 2006; 6, 690-692.

[2] Stourač $\mathrm{P}$, Kuchařová E, Křikava I, Malý R, Kosinová M, Harazim H, Smékalová O, Bártíková I, Stoudek R, Janků P, Huser M, Wágnerová K, Haklová O, Hakl L, Schwarz D, Zelinková H, Littnerová S, Jarkovský J, Gál R, Sevčík P. Establishment and evaluation of a post caesarean acute pain service in a perinatological center:retrospective observational study. Ceska Gynekol. 2014 Fall;79(5):363-370

[3] Granot, M., Lowenstein, L., Yarnitsky, D., Tamir, A., \& Zimmer, E.Z. Post cesarean section pain prediction by preoperative experimental pain assessment. Anesthesiol; 2004; 98(6), 1422-6.

[4] Yildirim, G., \& Sahin, N.H. The effect of breathing and skin stimulation on labour pain perception of Turkish women. Pain Research \& Management; 2004; 9(4), 183-7.

[5] Smith, C.A., Collins, C.T., Cyna, A.M., \& Crowther, C.A. Complementary and alternative therapies for pain management in Labour. Cochrane Database of Systematic Reviews; 2006;18(4), CD003521.

[6] Marzouk T, Barakat R, Ragab A, Badria F, Badawy A. Lavender-thymol as a new topical aromatherapy preparation for episiotomy: A randomised clinical trial. J Obstet Gynaecol. $2014 ; 10: 1-4$.

[7] Kim, J.T., Wajda, M., Cuff, G., Serota, D., Schlame, M., Axelrod, D.M., Guth, A.A., \& Bekker, A.Y. (2006). Evaluation of aromatherapy in treating postoperative pain: Pilot study. World Institute of Pain Practice; 2006; 6 (4), 273277 .

[8] Hadi, N., \& Hanid, A.A. Lavender essence for post cesarean pain. Pakistan J Biolo Sci; 2011; 14(11), 664.667.

[9] Nesami, M.B., Espahbodi, F., Nikkhah, A., Shorofi, S.A., \& Charati, J.Y. The effects of lavender aromatherapy on pain following needle insertion into a fistula in hemodialysis patients. Complement Ther Clin Pract. 2014 ;20(1):1-4

[10] Zahra, A., \& Leila, M.S. Lavender aromatherapy massages in reducing labor pain and duration of labor: A randomized controlled trial. African Journal of Pharmacy and Pharmacology; 2013; 7(8), 426-430.

[11] Henry, A., \& Nand, S., Intrapartum pain management at the Royal Hospital for Women: Australia and New Zealand Journal of Obstetrics and Gynecology, 2004; 44(4):307-317.

[12] Melzack R, Katz J. Measurement of pain. Surg Clin North Am 1999; 79:231-252.

[13] Gaston-Johansson F. Measurement of pain: the psychometric properties of the Pain-O-meter, a simple inexpensive pain assessment tool that could change health care practices. J Pain and Symptom Management 1996; 12 (3), 172-181.

[14] Fríguls B1, Joya X, García-Algar O, Pallás CR, Vall O, Pichini S. A comprehensive review of assay methods to determine drugs in breast milk and the safety of breastfeeding when taking drugs. Anal Bioanal Chem. 2010 Jun;397(3):1157-79

[15] Pollard, K.R. Introducing aromatherapy as a form of pain management into a delivery suite. Journal of the Association of Chartered Physiotherapists in Women's Health; 2008; 103, $12-16$.

[16] Sobhani, A., Sharemi, H., Orangpur, R., Shokuhi, F., \& Oudi, M. Effect of lavender oil in cesarian pain relief. J Gilan Univ Med Sci; 2007; 16(62), 80-86.

[17] Olapour, A., Behaeen, K., Akhondzadeh, R., Soltani, F., Razavi, S.F., \& Bekhradi, R. The effect of inhalation of aromatherapy blend containing Lavender essential oil on cesarean postoperative pain. Anesthesiol Pain Med; 2013; 3(1), 203-7.

[18] Sheikhan, F., Jahdi, F., Khoei, E.M., Shamsalizadeh, N., Sheikhan, M., \& Haghani, H. Episiotomy pain relief: Use of Lavender oil essence in primiparous Iranian women. Complement Ther Clin Pract. 2012 Feb;18(1):66-70

[19] Masoumi, Z., Keramat, A., \& Hajiaghaee, R. Systemic review on effect of herbal medicine on pain after perineal episiotomy and cesarean cutting. J Med Plants;2011; 4(40), 1-6.

[20] Soltani, R., Soheilipour, S., Hajhashemi, V., Asghari, G., Bagheri, M., \& Molavi, M. Evaluation of the effect of aromatherapy with lavender essential oil on posttonsillectomy pain in pediatric patients: A Randomized Controlled Trial; Int J Pediatr Otorhinolaryngol. 2013 Sep;77(9):1579-81

[21] Seraji, A., \& Vakilian, K. The comparison between the effects of aromatherapy with lavender and breathing techniques on the reduction of labor pain. Complement Med; 2011; 1(1), 31-39

[22] Shahnazi M, Nikjoo R, Yavarikia P, Mohammad-AlizadehCharandabi S. Inhaled lavender effect on anxiety and pain caused from intrauterine device insertion. J Caring Sci. 2012 Nov 28;1(4):255-61. 